\title{
The epigenetic signature of systemic insulin resistance in obese women
}

\author{
Peter Arner $^{1}$ - Anna-Stina Sahlqvist ${ }^{2}$ - Indranil Sinha ${ }^{3} \cdot \mathrm{Huan}_{\mathrm{Xu}^{4}} \cdot \mathrm{Xiang}_{\mathrm{Yao}}{ }^{5}$. \\ Dawn Waterworth ${ }^{6}$ - Deepak Rajpal ${ }^{6}$ A. Katrina Loomis ${ }^{7}$. \\ Johannes M. Freudenberg ${ }^{6}$ • Toby Johnson ${ }^{2}$ - Anders Thorell ${ }^{8,9} \cdot$ Erik Näslund $^{9}$ • \\ Mikael Ryden ${ }^{1}$ - Ingrid Dahlman ${ }^{1}$
}

Received: 21 June 2016 / Accepted: 13 July 2016 /Published online: 18 August 2016

(C) The Author(s) 2016. This article is published with open access at Springerlink.com

\begin{abstract}
Aims/hypothesis Insulin resistance (IR) links obesity to type 2 diabetes. The aim of this study was to explore whether white adipose tissue (WAT) epigenetic dysregulation is associated with systemic IR by genome-wide CG dinucleotide $(\mathrm{CpG})$ methylation and gene expression profiling in WAT from insulin-resistant and insulin-sensitive women. A secondary aim was to determine whether the DNA methylation signature in peripheral blood mononuclear cells (PBMCs) reflects WAT methylation and, if so, can be used as a marker for systemic IR.

Methods From 220 obese women, we selected a total of 80 individuals from either of the extreme ends of the distribution

Electronic supplementary material The online version of this article (doi:10.1007/s00125-016-4074-5) contains peer-reviewed but unedited supplementary material, which is available to authorised users.
\end{abstract}

Ingrid Dahlman

ingrid.dahlman@ki.se

1 Department of Medicine, Karolinska Institutet, Karolinska University Hospital, C2:94, Huddinge, S-141 86 Stockholm, Sweden

2 GlaxoSmithKline R\&D, Stevenage, UK

3 Department of Biosciences and Nutrition, Karolinska Institutet, Stockholm, Sweden

4 GlaxoSmithKline R\&D, Research Triangle Park, NC, USA

5 Computational and Systems Biology, Discovery Sciences, Janssen Pharmaceutical, Research \& Development, LLC, San Diego, CA, USA

6 GlaxoSmithKline R\&D, King of Prussia, PA, USA

7 Pfizer Worldwide Research and Development, Groton, CT, USA

8 Department of Surgery, Ersta Hospital, Stockholm, Sweden

9 Department of Clinical Sciences, Karolinska Institutet, Danderyd Hospital, Danderyd, Sweden curve of HOMA-IR, an indirect measure of systemic insulin sensitivity. Genome-wide transcriptome and DNA CpG methylation profiling by array was performed on subcutaneous (SAT) and visceral (omental) adipose tissue (VAT). CpG methylation in PBMCs was assayed in the same cohort.

Results There were 647 differentially expressed genes (false discovery rate [FDR] 10\%) in SAT, all of which displayed directionally consistent associations in VAT. This suggests that IR is associated with dysregulated expression of a common set of genes in SAT and VAT. The average degree of DNA methylation did not differ between the insulin-resistant and insulin-sensitive group in any of the analysed tissues/cells. There were 223 IRassociated genes in SAT containing a total of 336 nominally significant differentially methylated sites (DMS). The 223 IRassociated genes were over-represented in pathways related to integrin cell surface interactions and insulin signalling and included COL5A1, GAB1, IRS2, PFKFB3 and PTPRJ. In VAT there were a total of 51 differentially expressed genes (FDR 10\%); 18 IR-associated genes contained a total of 29 DMS. Conclusions/interpretation In individuals discordant for insulin sensitivity, the average DNA CpG methylation in SAT and VAT is similar, although specific genes, particularly in SAT, display significantly altered expression and DMS in IR, possibly indicating that epigenetic regulation of these genes influences metabolism.

Keywords CpG island · DNA methylation · Visceral adipose tissue

$\begin{array}{ll}\text { Abbreviations } \\ \text { CpG } & \text { CG dinucleotides } \\ \text { DMS } & \text { Differentially methylated sites } \\ \text { FDR } & \text { False discovery rate } \\ \text { IR } & \text { Insulin resistance }\end{array}$




$\begin{array}{ll}\text { PBMC } & \text { Peripheral blood mononuclear cell } \\ \text { qPCR } & \text { Quantitative real-time PCR } \\ \text { SAT } & \text { Subcutaneous adipose tissue } \\ \text { TRAIL } & \text { TNF-related apoptosis-inducing ligand } \\ \text { UTR } & \text { Untranslated region } \\ \text { VAT } & \text { Visceral adipose tissue } \\ \text { VEGFR } & \text { Vascular endothelial growth factor receptor } \\ \text { WAT } & \text { White adipose tissue }\end{array}$

\section{Introduction}

The impaired ability of insulin to induce cellular responses (i.e. insulin resistance [IR]) is a pathophysiological mechanism that links obesity to metabolic disorders such as type 2 diabetes and cardiovascular disease [1]. Both genetic and epigenetic factors are implicated in the development of systemic IR [2], which may be characterised by elevated circulating levels of insulin in the fasting state despite normal or elevated glucose levels. The association between IR and excess abdominal fat, in particular in the intra-abdominal or visceral adipose tissue (VAT) depot, is believed to be mediated by increased spontaneous hydrolysis of lipids (i.e. adipocyte lipolysis) [3]. Released NEFA can induce IR in the liver [4]. In addition, systemic IR is characterised by ectopic triacylglycerol accumulation in skeletal muscle and the liver [5]. Other pathways implicated in systemic IR include low-grade inflammation in white adipose tissue (WAT) [6].

An unfavourable intrauterine environment is associated with IR in adulthood suggesting a, possibly epigenetically regulated, metabolic memory [7]. The term 'epigenetics' refers to stable long-term alterations in the transcriptional potential of cells and includes histone modifications and DNA methylation, the latter occurring mainly in the context of CG dinucleotides (CpGs) [8]. In any given individual, the epigenetic profiles can differ substantially between different organs and cell types [9]. In WAT, global as well as site-specific differences in $\mathrm{CpG}$ methylation have been associated with obesity and type 2 diabetes [10-12]. A recent epigenomewide association study identified one locus where $\mathrm{CpG}$ methylation in $\mathrm{CD}^{+} \mathrm{T}$ cells is significantly associated with IR [13]. However, to our knowledge, no study of genome-wide $\mathrm{CpG}$ methylation profiling in the organs directly implicated in the development of IR has previously been reported.

The aim of this study was to explore whether systemic IR is associated with epigenetic dysregulation of WAT, determined by genome-wide $\mathrm{CpG}$ methylation and gene expression profiling in subcutaneous adipose tissue (SAT) and VAT. Adipose tissue is not ideal for routine clinical examinations; therefore, a secondary aim was to determine whether the DNA methylation signature in peripheral blood mononuclear cells (PBMCs) reflects WAT methylation and may thus be used as a marker for systemic IR.

\section{Methods}

Participants and clinical evaluation The 80 women included in this study were selected from the extremes of insulin sensitivity, as measured by HOMA-IR [14], from 220 obese women who participated in a clinical trial on the effect of bariatric surgery (ClinicalTrial.gov registration no. NCT01785134). The sample size was selected based on previous experience from transcriptome and DNA methylation profiling on WAT in relation to clinical metabolic phenotypes [10]. Of the 80 women, none had undergone any active weight-reducing attempt for at least 6 months prior to surgery. Eight women were diagnosed with hypertension, seven of which were prescribed antihypertensive treatment (ACE inhibitors, $n=3$; diuretics, $n=2$; calcium-channel blockers, $n=2 ; \beta$-blockers, $n=5$ ). Eleven patients were prescribed antidepressants, and one patient was taking methylphenidate for attention deficit hyperactivity disorder. Mild impaired kidney function $(n=1)$, obstructive sleep apnoea $(n=1)$, von Willebrand's disease $(n=1)$ and substituted vitamin B12 deficiency $(n=1)$ were each diagnosed. Otherwise, participants were healthy according to medical history. All sampling and measurements were performed before or during bariatric surgery (laparoscopic gastric bypass).

Participants were investigated at 08:00 hours after an overnight fast. Anthropometric measurements were performed followed by venous blood sampling. Blood glucose and lipids were analysed at the Karolinska University hospital's routine chemistry laboratory (Stockholm, Sweden). Plasma insulin was measured by ELISA (Mercodia, Uppsala, Sweden) as previously described [15]. Insulin sensitivity was assessed by HOMA-IR and was calculated from fasting measures of glucose and insulin as described [14]. High HOMA-IR values indicate IR. The 40 women with the highest HOMA-IR values and the 40 women with the lowest values were selected for inclusion in the present study. PBMCs were isolated in BD Vacutainer Cell Preparation tubes (Becton, Dickinson San Jose, CA, USA) and stored as pellets at $-80^{\circ} \mathrm{C}$ for further analysis.

The study was approved by the Regional Ethics Committee in Stockholm and all participants gave their written informed consent prior to participation. The study was carried out in accordance with the principles of the Declaration of Helsinki as revised in 2008 .

WAT sampling Biopsies from the abdominal SAT depot were obtained from the surgical incision. Omental adipose tissue (visceral adipose tissue [VAT]) specimens were obtained using ultrasound scissors immediately after surgeons entered the abdominal cavity. Participants were fasted overnight and $154 \mathrm{mmol} / \mathrm{l} \mathrm{NaCl}$ was given by i.v. infusion until adipose tissue specimens were removed. All WAT samples were rapidly rinsed in $\mathrm{NaCl}(154 \mathrm{mmol} / \mathrm{l})$ and specimens of $300 \mathrm{mg}$ unfractionated WAT were immediately frozen in liquid 
nitrogen and kept at $-70^{\circ} \mathrm{C}$ for subsequent DNA and RNA preparation.

Global transcriptome assays From high-quality total RNA we prepared and hybridised biotinylated complementary RNA to GeneChip Human Transcriptome Arrays 2.0 (HTA; Affymetrix, Santa Clara, CA, USA) as described in the electronic supplementary material (ESM) Methods. Of the 23,442 probesets annotated with a gene symbol, 5860 (25\%) transcripts with the lowest mean expression and $5860(25 \%)$ with the lowest variation in expression (i.e. SD divided by mean expression) were excluded, resulting in 11,722 probesets being taken forward for subsequent analysis of differentially expressed genes. The applied cut-off for mean expression was used to exclude a set of organ-specific genes that should not be expressed in adipose tissue according to the literature. Webgestalt (http://bioinfo. vanderbilt.edu/webgestalt/) was used to identify pathways overrepresented among differentially expressed genes and differentially methylated sites (DMS) [16].

DNA methylation microarray assays DNA extracted from SAT and VAT pieces, as well as from PBMCs, was assayed using the Infinium Human Methylation 450 (450 K) BeadChips (Illumina, San Diego, CA, USA) as described in ESM Methods [17]. BeadChip images were processed as described in ESM Methods. For differential methylation analysis, $\beta$ values were converted to $M$ values $\left(M=\log _{2}[\beta /(1-\beta)]\right)$, which have a more appropriate distribution for statistical tests for comparisons between groups. Before analysis of DMS a number of filtering steps were performed resulting in 112,057 (SAT), 124,089 (VAT) and 99,462 (PBMCs) probes, respectively, being taken forward to identify DMS.

Methylation data have been deposited in the National Center for Biotechnology Information Gene Expression Omnibus (GEO; http://ncbi.nlm.nih.gov/geo, accession number GSE76399).

Validation experiments Ten differentially expressed genes with DMS in SAT were selected for validation experiments. The genes were selected because they displayed consistent results in SAT and either VAT or PBMCs, or because they were mentioned in the Discussion. Gene expression was measured by quantitative real time-PCR (qPCR) using recommended inventoried Taqman assays from Applied Biosystems (Thermo Fisher Scientific, Waltham, MA, USA). Each sample was analysed once. Group assignment was blinded during experimentation.

Eleven DMS in SAT, in seven genes, were selected for validation by EpiTYPER (Agena Biosciences, San Diego, CA, USA), see ESM Methods for details. We were unable to design EpiTYPER assays for DMS in some differentially expressed genes validated by qPCR. We therefore selected a
DMS COL4A1 for confirmation although this gene was not quantified by qPCR.

Statistical analysis We used the Bioconductor package, Limma (https://bioconductor.org/packages/release/bioc/html/limma. html) to analyse the methylation $M$ values to identify DMS between insulin-resistant and insulin-sensitive women, adjusting for BMI and age [18-20]. A threshold of $p<0.05$ was used in the epigenetic analysis. We also used parametric analysis in Limma to compare gene expression levels $\left(\log _{2}\right)$ between the insulinresistant and insulin-sensitive groups adjusting for BMI. In transcriptome analysis a thresholds false discovery rate (FDR) of $10 \%$ was used. A $t$ test was applied to compare clinical phenotypes, average global DNA methylation and validation results (qPCR and EpiTYPER) between the insulin-resistant and insulin-sensitive groups; a $\chi^{2}$ test was used to compare proportions.

\section{Results}

Clinical characteristics of participants The clinical characteristics of the included participants are detailed in Table 1. As expected from the study design, the insulin-resistant group had substantially higher HOMA-IR, fasting plasma glucose and fasting serum insulin as compared with the insulinsensitive group. The insulin-resistant group also displayed higher body weight, BMI, waist circumference and plasma triacylglycerol concentrations. Total and HDL-cholesterol levels were similar and there was no significant difference in age when comparing the groups. Thus, the groups were representative of the insulin-resistant or insulin-sensitive state.

Table 1 Clinical characteristics of cohort

\begin{tabular}{llll}
\hline Characteristic & $\begin{array}{l}\text { Insulin } \\
\text { resistant } \\
(n=40)\end{array}$ & $\begin{array}{l}\text { Insulin } \\
\text { sensitive } \\
(n=40)\end{array}$ & $p$ value \\
\hline Age (years) & $36.4 \pm 6.3$ & $35.7 \pm 5.7$ & 0.57 \\
Weight $(\mathrm{kg})$ & $116.8 \pm 16.7$ & $110.1 \pm 11.7$ & 0.04 \\
BMI $\left(\mathrm{kg} / \mathrm{m}^{2}\right)$ & $42.7 \pm 4.7$ & $39.1 \pm 3.0$ & $8.37 \times 10^{-5}$ \\
Waist circumference $(\mathrm{cm})$ & $129.8 \pm 11.9$ & $122.3 \pm 11.1$ & 0.0061 \\
fP Glucose (mmol/1) & $6.0 \pm 1.3$ & $5.1 \pm 0.4$ & $9.07 \times 10^{-5}$ \\
fS Insulin (pmol/l) & $127 \pm 39$ & $29 \pm 8$ & $1.29 \times 10^{-25}$ \\
$\begin{array}{l}\text { HOMA-IR } \\
\text { fS Cholesterol (mmol/l) }\end{array}$ & $5.6 \pm 2.0$ & $1.1 \pm 0.3$ & $7.11 \times 10^{-23}$ \\
fS HDL-cholesterol & $1.1 \pm 0.4$ & $1.2 \pm 0.3$ & 0.78 \\
$\quad(\mathrm{mmol} / \mathrm{l})$ & $1.45 \pm 0.7$ & $1.02 \pm 0.4$ & 0.000786 \\
fS Triacylglycerols & & & \\
$\quad(\mathrm{mmol} / \mathrm{l})$ & & & \\
\hline
\end{tabular}

Data are means $\pm \mathrm{SD}$; all participants are women

Groups were compared with $t$ test

$\mathrm{fP}$, fasting plasma; $\mathrm{fS}$, fasting serum 
Transcriptome profile in SAT and VAT Comparison of the expression levels of 11,722 transcripts between insulinresistant and insulin-sensitive women adjusted for BMI identified 647 differentially expressed genes in SAT (represented by 656 probesets, FDR 10\% [see ESM Table 1]). Expression of ten differentially expressed genes in SAT was confirmed by qPCR; all displayed directionally consistent results between insulin-resistant and insulin-sensitive women in both microarray and qPCR analysis, of which eight genes remained nominally significant with qPCR (ESM Table 2). We compared these results with previously reported genome-wide transcriptome analyses of SAT between insulin-resistant and insulin-sensitive individuals according to HOMA-IR. Among 321 differentially expressed genes in SAT of 40 European-Americans, reported by Elbein et al (FDR 5\%) [21], 26 genes overlapped with the present study, all of which displayed directionally consistent change in expression $\left(p<3.4 \times 10^{-7}\right)$. Among 373 differentially expressed genes in SAT (top/bottom 20\%) from 323 individuals, reported by Qatanani et al [22], 19 genes overlapped with the present study and 18 of these displayed directional consistency $\left(p<9.6 \times 10^{-5}\right)($ ESM Table 1$)$.

The 647 differentially expressed genes were over-represented for a number of pathways (Table 2), including pathways related to inflammation and immunity (e.g. TNF-related apoptosis-inducing ligand [TRAIL] signalling, IL3-mediated signalling and vascular endothelial growth factor receptor [VEGFR] signalling), which is in agreement with the findings by Elbein et al [21] and Qatanani et al [22]. As expected, genes in the insulin signalling pathway were also over-represented. The 70 differentially expressed genes in the insulin signalling pathway are shown in ESM Table 3 and include IRS2, which was downregulated by $15 \%$, and $I L 6 R$, which was upregulated by $7 \%$ in insulin-resistant women.

In VAT there were 51 differentially expressed genes (represented by 52 probesets) between insulin-resistant and insulin-sensitive women at FDR 10\% (Table 3). For comparison, Qatanani et al [22] reported 788 differentially expressed genes in VAT between insulin-resistant and insulin-sensitive individuals (top/bottom 20\%), out of which eight genes overlapped with the 51 differentially expressed genes in the present study (i.e. GSDMB [fold changes insulin-resistant vs insulin-sensitive: 0.82], AGPAT9 [0.78], PAIP2B [0.85], CA3 [0.45], SERPINI1 [0.91], RASSF4 [1.13], MYD88 [1.09], SLCO2B1 [1.24]); all eight genes displayed directionally consistent expression in both studies $\left(p<4.7 \times 10^{-3}\right)$ [22] (Table 3). The 51 differentially expressed genes in VAT in our study were not over-represented for any specific pathway.

To assess possible depot-specific differences in gene expression, we overlapped the gene array data from VAT and SAT. ESM Fig. 1 a shows a histogram of the per-gene correlation between gene expression in VAT and SAT tissue samples and Fig. 1b shows a boxplot of between-sample correlation. As
Table 2 Over-representation of specific gene-sets among differentially expressed genes in SAT between insulin-resistant and insulin-sensitive women $^{\mathrm{a}}$

\begin{tabular}{llll}
\hline Pathway $^{\mathrm{c}}$ & Observed $^{\mathrm{b}}$ & Expected $^{\mathrm{b}}$ & $\begin{array}{l}\text { Adjusted } \\
p \text { value }\end{array}$ \\
\hline $\begin{array}{l}\text { TRAIL signalling pathway } \\
\text { Signalling events mediated by }\end{array}$ & 73 & 49 & 0.0024 \\
$\quad$ VEGFR1 and VEGFR2 & & 48 & 0.0024 \\
$\begin{array}{l}\text { GMCSF-mediated signalling } \\
\quad \text { events }\end{array}$ & 70 & 48 & 0.0024 \\
$\begin{array}{l}\text { IL3-mediated signalling events } \\
\text { PAR1-mediated thrombin }\end{array}$ & 70 & 48 & 0.0024 \\
$\quad$ signalling events & 70 & 48 & 0.0024 \\
S1P1 pathway & 70 & 47 & 0.0024 \\
IFN- $\gamma$ pathway & 70 & 48 & 0.0024 \\
ErbB1 downstream signalling & 70 & 47 & 0.0024 \\
$\begin{array}{l}\beta_{1} \text { integrin cell surface interactions } \\
\text { Urokinase-type plasminogen }\end{array}$ & 78 & 50 & 0.0024 \\
$\quad$ activator and uPAR-mediated & 70 & 47 & 0.0024 \\
$\quad$ signalling & & & \\
Plasma membrane oestrogen & 71 & 48 & 0.0024 \\
$\quad$ receptor signalling & & & \\
IGF1 pathway & 70 & 47 & 0.0024 \\
Insulin pathway & 70 & 47 & 0.0024 \\
Arf6 signalling events & 70 & 47 & 0.0024 \\
\hline
\end{tabular}

${ }^{a}$ Webgestalt was used to identify over-represented gene-sets (Pathway commons) among 647 differentially expressed genes as compared with all 11,722 analysed genes using default settings

${ }^{\mathrm{b}}$ Number of differentially expressed genes

Arf6, ADP-ribosylation factor 6; ErbB1, epidermal growth factor receptor; GMCSF, granulocyte-macrophage colony-stimulating factor; PAR1, proteinase-activated receptor 1; S1P1, sphingosine-1-phosphate receptor; uPAR, plasminogen activated receptor urokinase type

expected, within-participant correlation is higher than between-participant. All 51 differentially expressed genes in VAT displayed directionally consistent differences in expression in SAT between insulin-resistant and insulin-sensitive women, and 30 of these genes were significant (FDR 10\%; Table 3). Conversely, of the 647 differentially expressed genes in SAT, all displayed directionally consistent differences in VAT (ESM Table 1), 209 of which were nominally significant $(p \leq 0.05)$. The magnitude of the difference in expression of these genes between insulin-resistant and insulin-sensitive women was comparable between VAT (median difference in expression 8.8\%; range 3.8-23.9\%) and SAT (median 10.7\%; range 4.6-38.5\%). For individual genes, the median difference in ratio of expression between insulin-resistant and insulinsensitive women was $0.027 \%$ (range $0.005-23.0 \%$ ) between adipose depots. Together, these comparisons suggest that in the present cohort, IR is associated with similar dysregulations of gene expression in the examined WAT depots.

Global pattern of $\mathbf{C p G}$ methylation The average degree of DNA methylation (i.e. the average $\beta$ value for all probes 
Table 3 Differentially expressed genes in VAT between insulin-resistant and insulin-sensitive women

\begin{tabular}{|c|c|c|c|c|c|c|c|c|c|}
\hline \multirow[t]{2}{*}{ Probeset } & \multirow[t]{2}{*}{ Gene } & \multicolumn{4}{|l|}{ VAT } & \multirow{2}{*}{$\begin{array}{l}\mathrm{VAT}^{\mathrm{a}} \\
\mathrm{IR} / \mathrm{IS}\end{array}$} & \multicolumn{3}{|l|}{ SAT } \\
\hline & & IR & IS & IR/IS & Adjusted $p$ value ${ }^{\mathrm{b}}$ & & IS & IR/IS & Adjusted $p$ value $\mathrm{b}^{\mathrm{b}}$ \\
\hline TC09001184.hg.1 & PGM5-AS1 & $174(27)$ & $219(34)$ & 0.79 & 0.002 & & 127 & 0.87 & \\
\hline TC09001281.hg.1 & GKAP1 & $56(4)$ & $63(6)$ & 0.89 & 0.002 & & 56 & 0.90 & 0.021 \\
\hline TC17002851.hg.1 & $G S D M B$ & $92(10)$ & $112(19)$ & 0.82 & 0.0082 & 0.84 & 91 & 0.84 & 0.016 \\
\hline TC04000460.hg.1 & AGPAT9 & $70(12)$ & 89 (18) & 0.78 & 0.022 & 0.79 & 55 & 1.00 & \\
\hline TC12000227.hg.1 & PDE3A & $109(22)$ & $133(22)$ & 0.82 & 0.028 & & 100 & 0.82 & 0.033 \\
\hline TC09001585.hg.1 & $S C A I$ & $62(5)$ & $69(7)$ & 0.90 & 0.034 & & 67 & 0.88 & 0.016 \\
\hline TC15000030.hg.1 & GOLGA8IP & 195 (17) & $217(22)$ & 0.90 & 0.034 & & 186 & 0.93 & 0.08 \\
\hline TC05000782.hg.1 & ARHGAP26 & 127 (18) & $109(13)$ & 1.16 & 0.034 & & 111 & 1.09 & 0.078 \\
\hline TC22000816.hg.1 & ST13 & 499 (38) & $558(57)$ & 0.89 & 0.035 & & 537 & 0.89 & 0.016 \\
\hline TC20000575.hg.1 & SIGLEC1 & $189(30)$ & $164(18)$ & 1.15 & 0.035 & & 164 & 1.11 & 0.072 \\
\hline TC09000495.hg.1 & $A N P 32 B$ & $215(14)$ & $237(21)$ & 0.91 & 0.038 & & 244 & 0.92 & 0.019 \\
\hline TC15000157.hg.1 & GOLGA8J & $228(24)$ & $257(28)$ & 0.89 & 0.038 & & 203 & 0.91 & 0.03 \\
\hline TC05000212.hg.1 & ISL1 & $80(10)$ & $99(25)$ & 0.80 & 0.041 & & 29 & 0.99 & \\
\hline TC02001974.hg.1 & $P A I P 2 B$ & $96(10)$ & $114(17)$ & 0.85 & 0.042 & 0.93 & 87 & 0.89 & \\
\hline TC15002013.hg.1 & TARSL2 & $79(4)$ & $86(7)$ & 0.92 & 0.043 & & 83 & 0.94 & 0.078 \\
\hline TC05001954.hg.1 & FAT2 & $56(7)$ & $49(5)$ & 1.14 & 0.043 & & 76 & 1.11 & \\
\hline TC01003789.hg.1 & ST13P19 & $52(5)$ & $58(6)$ & 0.89 & 0.043 & & 51 & 0.91 & 0.048 \\
\hline TC15002805.hg.1 & $U L K 4 P 1$ & $172(38)$ & $220(50)$ & 0.78 & 0.047 & & 142 & 0.82 & 0.019 \\
\hline TC17001703.hg.1 & MBTD1 & $106(7)$ & $116(11)$ & 0.91 & 0.048 & & 109 & 0.92 & 0.031 \\
\hline TC20000926.hg.1 & $K C N B 1$ & $150(20)$ & $127(23)$ & 1.18 & 0.052 & & 159 & 1.12 & \\
\hline TC06004132.hg.1 & MOCS1 & $162(33)$ & $205(40)$ & 0.79 & 0.052 & & 190 & 0.86 & 0.014 \\
\hline TC05001714.hg.1 & $L O X$ & $206(38)$ & $169(29)$ & 1.22 & 0.052 & & 291 & 1.07 & \\
\hline TC05001317.hg.1 & CCL28 & $58(4)$ & $63(6)$ & 0.91 & 0.058 & & 61 & 0.97 & \\
\hline TC07001811.hg.1 & $A A S S$ & $103(11)$ & $118(16)$ & 0.88 & 0.059 & & 95 & 0.85 & 0.021 \\
\hline TC08002581.hg.1 & $C A 3$ & $110(59)$ & $242(176)$ & 0.45 & 0.062 & 0.42 & 99 & 0.81 & \\
\hline TC03000892.hg.1 & SERPINII & $49(5)$ & $54(6)$ & 0.91 & 0.062 & 0.81 & 36 & 0.95 & \\
\hline TC11000898.hg.1 & NAALAD2 & $39(7)$ & $48(10)$ & 0.80 & 0.066 & & 54 & 0.74 & 0.019 \\
\hline TC15000160.hg.1 & $U L K 4 P 3$ & 147 (37) & $188(43)$ & 0.78 & 0.07 & & 115 & 0.80 & 0.02 \\
\hline TC01000619.hg.1 & $C D K N 2 C$ & $110(18)$ & $134(25)$ & 0.82 & 0.072 & & 134 & 0.92 & \\
\hline TC10000289.hg.1 & RASSF4 & $142(19)$ & $126(13)$ & 1.13 & 0.072 & 1.23 & 153 & 1.12 & 0.059 \\
\hline TC19000034.hg.1 & $C I R B P$ & $565(44)$ & $615(54)$ & 0.92 & 0.072 & & 564 & 0.97 & \\
\hline TC18000224.hg.1 & PHLPPI & $91(6)$ & $101(9)$ & 0.91 & 0.072 & & 105 & 0.89 & 0.03 \\
\hline TC13000436.hg.1 & $U P F 3 A$ & 177 (13) & $190(16)$ & 0.93 & 0.072 & & 209 & 0.96 & \\
\hline TC04001410.hg.1 & $A D H 1 B$ & $3013(467)$ & $3478(495)$ & 0.87 & 0.074 & & 3236 & 0.80 & 0.017 \\
\hline TC15001546.hg.1 & $D A P K 2$ & $146(21)$ & $171(26)$ & 0.86 & 0.074 & & 159 & 0.85 & 0.0088 \\
\hline TC04001305.hg.1 & CXCL10 & $60(57)$ & $36(11)$ & 1.67 & 0.074 & & 57 & 0.99 & \\
\hline TC09000319.hg.1 & TJP2 & $166(14)$ & $179(14)$ & 0.93 & 0.074 & & 194 & 0.98 & \\
\hline TC03000187.hg.1 & MYD88 & $172(16)$ & $158(14)$ & 1.09 & 0.076 & 1.12 & 193 & 1.06 & \\
\hline TC07001493.hg.1 & $G T F 2 I R D 2 P 1$ & $151(14)$ & $163(15)$ & 0.92 & 0.081 & & 158 & 0.92 & \\
\hline TC02002891.hg.1 & $A R L 4 C$ & $77(9)$ & $69(10)$ & 1.12 & 0.081 & & 61 & 1.09 & \\
\hline TC09002904.hg.1 & NIPSNAP3B & $78(20)$ & $102(28)$ & 0.77 & 0.081 & & 96 & 0.77 & 0.019 \\
\hline TC12001300.hg.1 & $A B C C 9$ & $338(63)$ & $391(63)$ & 0.86 & 0.082 & & 630 & 0.75 & 0.0026 \\
\hline TC12001299.hg.1 & KCNJ8 & $129(11)$ & $142(14)$ & 0.91 & 0.088 & & 144 & 0.89 & 0.02 \\
\hline TC11000933.hg.1 & CEP57 & $98(7)$ & 107 (13) & 0.92 & 0.089 & & 110 & 0.89 & 0.019 \\
\hline TC11000802.hg.1 & $S L C O 2 B 1$ & $264(66)$ & $213(52)$ & 1.24 & 0.094 & 1.26 & 217 & 1.19 & 0.087 \\
\hline TC02000395.hg.1 & PNOI & $57(5)$ & $53(4)$ & 1.08 & 0.094 & & 71 & 1.06 & \\
\hline TC01001043.hg.1 & PHGDH & $119(15)$ & $135(22)$ & 0.88 & 0.094 & & 92 & 0.91 & \\
\hline
\end{tabular}


Table 3 (continued)

\begin{tabular}{|c|c|c|c|c|c|c|c|c|c|}
\hline \multirow[t]{2}{*}{ Probeset } & \multirow[t]{2}{*}{ Gene } & \multicolumn{4}{|l|}{ VAT } & \multirow{2}{*}{$\begin{array}{l}\mathrm{VAT}^{\mathrm{a}} \\
\mathrm{IR} / \mathrm{IS}\end{array}$} & \multicolumn{3}{|l|}{ SAT } \\
\hline & & IR & IS & IR/IS & Adjusted $p$ value ${ }^{\mathrm{b}}$ & & IS & IR/IS & Adjusted $p$ value ${ }^{\mathrm{b}}$ \\
\hline TC11001197.hg.1 & ADAMTS15 & $98(12)$ & $88(10)$ & 1.11 & 0.094 & & 110 & 1.28 & 0.021 \\
\hline TC18000132.hg.1 & $R N F 125$ & $95(10)$ & $109(15)$ & 0.88 & 0.094 & & 104 & 0.95 & \\
\hline TC02002086.hg.1 & $A N K R D 20 A 8 P$ & $42(6)$ & $47(7)$ & 0.91 & 0.094 & & 41 & 0.92 & 0.07 \\
\hline TC01001866.hg.1 & $A D C K 3$ & $181(13)$ & $201(23)$ & 0.90 & 0.095 & & 192 & 0.93 & 0.071 \\
\hline
\end{tabular}

Data are shown as average (SD) for VAT or average for SAT

${ }^{a}$ Comparison with published transcriptome profile [27] on VAT from insulin-resistant vs insulin-sensitive individuals

${ }^{\mathrm{b}}$ Gene expression was compared between groups using Limma and adjusting for BMI; threshold FDR < 10\%

IR, insulin-resistant; IS, insulin-sensitive

remaining after filtering) was compared between the insulinresistant and insulin-sensitive groups. There were no significant differences in either SAT (insulin-resistant $0.504 \pm 0.019$ [average $\beta$ value $\pm \mathrm{SD}$ ]); insulin-sensitive $0.507 \pm 0.013$ ), VAT (insulin-resistant $0.483 \pm 0.014$; insulin-sensitive 0.477 \pm 0.022 ) or PBMCs (insulin-resistant $0.508 \pm 0.020$; insulinsensitive $0.510 \pm 0.015)$. The average level of DNA methylation stratified by genome region in relation to $\mathrm{CpG}$ content and functional parts of genes is shown in Fig. 1.

DMS in SAT Comparison of CpG methylation in SAT between insulin-resistant and insulin-sensitive women was assessed at 112,057 sites. Although none of the DMS were significant after FDR correction, 10,746 were nominally significant with median differences in methylation of 0.024 (range $4 \times 10^{-4}$ to 0.092 ) between groups $(p \leq 0.05)$. These data were compared with results from other DNA methylation profiling studies on SAT applying the same $450 \mathrm{~K}$ platform. Nilsson et al reported, in a cohort of 56 individuals, 15,627 DMS $(q<0.15)$ in WAT associated with type 2 diabetes [10]; 671 of the DMS overlapped with those in the present study, of which 592 displayed directionally consistent differences in methylation in both cohorts $\left(p<2.7 \times 10^{-87)}\right.$ (ESM Table 4) [10]. In a study of 190 men and women, Rönn et al identified
Fig. 1 DNA methylation landscape in insulin-resistant vs insulin-sensitive women in SAT (a, d), VAT (b, e) and PBMCs (c, f). Based on Illumina annotation, 112,057 (SAT), 124,089 (VAT) and 99,462 (PBMCs) CpG probes were mapped to genome regions. We calculated the average level of DNA methylation within each of the insulin-resistant (black bars) and insulin-sensitive (white bars) groups stratified on genome region in relation to functional gene regions $(\mathbf{a}, \mathbf{b}, \mathbf{d})$ and $\mathrm{CpG}$ content (d, e, f). TSS1500, within $1500 \mathrm{bp}$ of transcriptional start site (TSS); TSS200, within $200 \mathrm{bp}$ of TSS. Genome locations: Island, $\mathrm{CpG}$ island; $\mathrm{N}$ Shelf, upstream CpG island shelf; N_Shore, upstream CpG island shore; S_Shore, downstream CpG island shore; S Shelf, downstream $\mathrm{CpG}$ island shelf; Open_sea; other $\mathrm{CpG}$ regions a

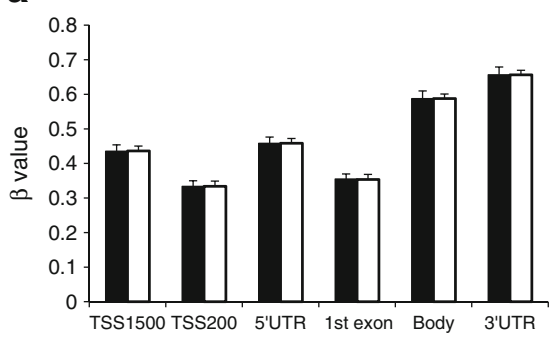

b

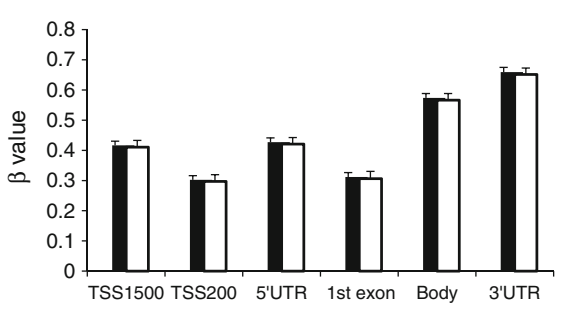

C

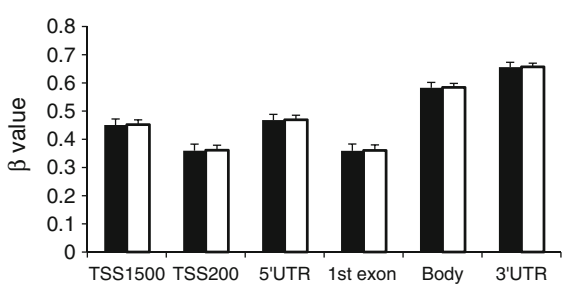

d

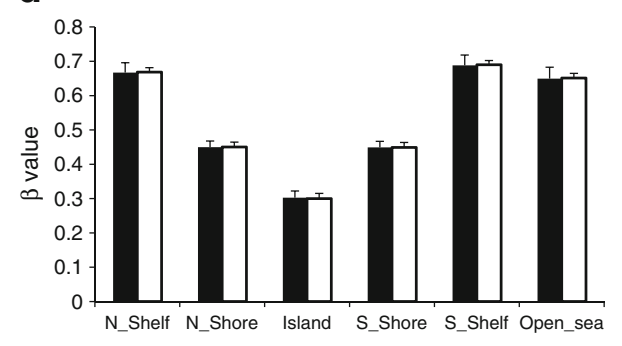

e

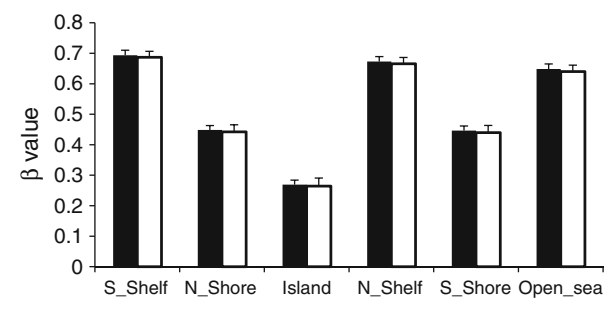

f

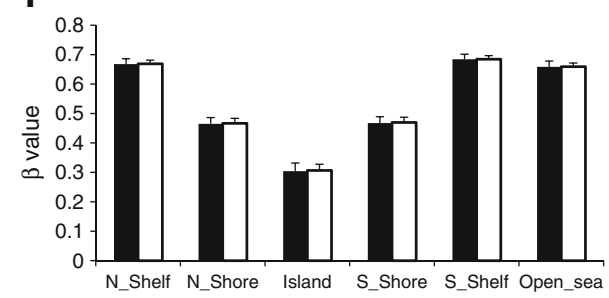


39,533 CpG sites whose methylation in WAT of women was associated with BMI. Of these BMI-associated CpG sites, 2052 overlapped with the present study and 1973 displayed directionally consistent differences in methylation $\left(p<1 \times 10^{-90}\right)($ ESM Table 4) [20]. Benton et al reported 3601 DMS before vs after weight loss induced by bariatric surgery [12]. Ninety-three DMS overlapped with the present study out of which 91 sites displayed directionally consistent results between obese individuals before weight loss and insulin-resistant individuals $\left(p<2.7 \times 10^{-20}\right)$ (ESM Table 4). Eleven DMS were confirmed by EpiTYPER; nine displayed directionally consistent results between insulin-resistant and insulin-sensitive women in both microarray and EpiTYPER analysis, of which four remained nominally significant, and three more were close to significance $(p<0.06)$ (ESM Table 2). It is worth noting that, of the DMS analysed by EpiTYPER, seven had been previously reported, all of which were confirmed by the present study.

Next, we merged the 647 differentially expressed genes in SAT with the 10,746 DMS and identified 223 IR-associated genes containing a total of 336 DMS (ESM Table 5). These genes are evenly distributed in the genome, and each gene contains one or a few DMS (Fig. 2). A subset of these genes is listed in Table 4. Twenty-nine genes displayed direct, positive or negative, correlation between gene expression and methylation (ESM Table 6). Whereas CpG methylation in 5, regions of genes has classically been associated with reduced gene expression, $\mathrm{CpG}$ methylation in gene bodies has been reported to stimulate gene expression [23]. It was therefore of interest to map the IR-associated DMS in relation to gene region, and relate the degree of methylation to gene expression. Among 158 DMS in 5' regions of genes, $67 \mathrm{CpG}$ sites displayed reciprocal direction of effect between gene expression and $\mathrm{CpG}$ methylation. Among 178 DMS in gene bodies and 3' untranslated regions (3'UTRs), 80 CpG sites displayed a positive association between changes in DNA methylation and gene expression. Thus, there was no evidence that DNA methylation in the 5' regions of genes preferentially repressed gene expression, nor the opposite in gene bodies.

The 223 IR-associated genes were over-represented for pathways related to integrin cell surface interactions, focal adhesion and insulin signalling (ESM Table 7). Data for the insulin signalling genes are shown in Table 5.

DMS in VAT CpG methylation in VAT was assessed at 124,089 sites. Although none of the DMS were significant after FDR correction, 10,217 were nominally significant $(p \leq 0.05)$ between insulin-resistant and insulin-sensitive women with median difference in methylation of 0.028 (range 0.001-0.105) (ESM Table 8). We mapped the 10,217 DMS from the present study to other DNA methylation profiling studies in VAT that used the $450 \mathrm{~K}$ platform. Benton et al reported 15 DMS in VAT before vs after weight loss induced by bariatric surgery, of which two CpG sites displayed nominally significant and directionally consistent results in the present study $(p<0.2)$ (ESM Table 8) [12]. Guenard et al listed 83 DMS in VAT associated with the metabolic syndrome [24] and, of these, none were differentially methylated in VAT between insulin-resistant and insulin-sensitive women in the present study. Finally, we compared results between SAT and VAT in the present study. Among nominally significant DMS between insulin-resistant and insulin-sensitive women, $1455 \mathrm{CpG}$ sites overlapped between SAT and VAT, 1406 of which displayed directionally consistent results between depots (ESM Table 8).

Next, we merged the 51 differentially associated expressed genes in VAT with the 10,217 DMS and thus identified 18 IRassociated genes containing a total of 29 DMS (Table 6). There were three DMS in two differentially expressed genes that were common between SAT and VAT; cg14229247 (in $A N P 32 B$ ), and $\operatorname{cg} 08400424$ and $\operatorname{cg} 11796181$ (both in ARHGAP26) (Table 6). cg14229247 in ANP32B could not be confirmed by EpiTYPER, whereas we were unable to design assays for the DMS in ARHGAP26, leaving some uncertainty to these results (ESM Table 2). Four genes displayed direct, positive or negative, correlation between gene expression and methylation in VAT (ESM Table 6). Of the 11 DMS in the $5^{\prime}$ region of genes, seven $\mathrm{CpG}$ sites displayed an inverse association between gene expression and methylation. Among 18 DMS in gene bodies and 3'UTR regions, two CpG sites displayed coherent changes.

DMS in PBMCs We investigated whether IR was associated with systemic epigenetic differences by analysing DNA methylation profiles in PBMCs. There were no significant DMS after correction for multiple testing among the 99,462 analysed $\mathrm{CpG}$ sites, although 2451 were nominally significant with median differences in methylation of 0.021 (range $7 \times 10^{-5}-0.130$ ) between groups $(p \leq 0.05)$ (ESM Table 9). There were 268 DMS that overlapped between SAT and PBMCs, of which 109 displayed directionally consistent results (ESM Table 4). Among DMS accompanied by differential gene expression in SAT, only three $\mathrm{CpG}$ sites displayed significant differential methylation in a consistent direction in PBMCs: ADAMTS2 cg26694831, average difference in $\beta$ value between the insulin-resistant and insulin-sensitive women in SAT -0.037 and PBMCs $-0.044(p=0.005)$, respectively; FIP1L1 cg19408398, average difference in SAT 0.026 and PBMCs 0.034 ( $p=0.012$ ), respectively; SAMD4A cg06633081 average difference in SAT -0.033 and PBMCs $-0.027(p=0.048)$, respectively. EpiTYPER analyses of these CpG sites in SAT were non-significant, although DMS in ADAMTS2 and FIP1L1 remained directionally consistent (ESM Table 2).

Cell-mixture-adjusted analysis of DMS We applied a reference-free algorithm for cell-mixture adjustment to detect 
Fig. 2 Chromosomal position of 223 IR-associated genes containing a total of 336 DMS. Inner circle shows gene expression data (blue, upregulated expression in IR; yellow, downregulated expression in IR), outer circle represents methylation data (blue, high methylation in IR; yellow, low methylation in IR)

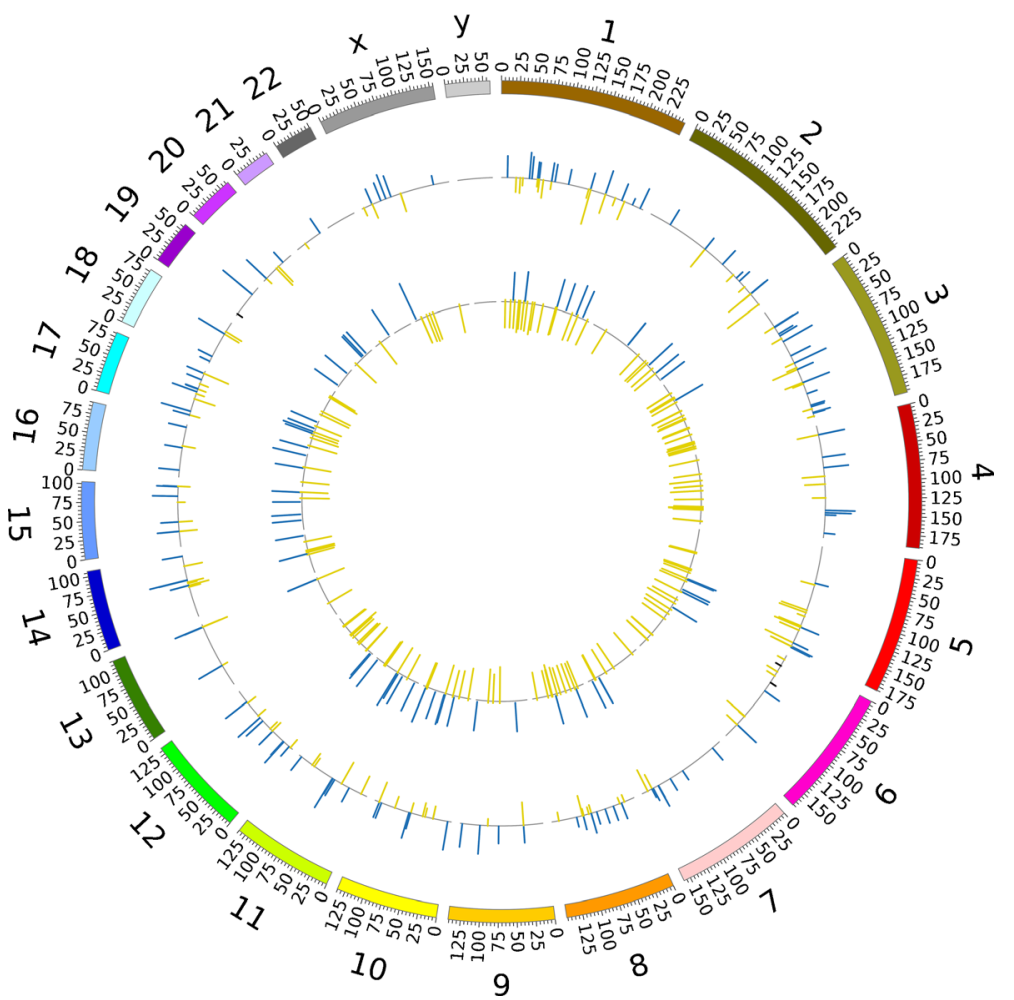

DMS, and compared the results with our original whole-tissuebased results [25]. There were 2669, 14,410, and 949 DMS in SAT, VAT and PBMCs, respectively, after cell-mixture adjustment. The number of DMS overlapping between the cellmixture-adjusted analysis and our original analysis was 948 for SAT, 2059 for VAT and 380 for PBMCs; of these 943, 1999 and 379 DMS, respectively, displayed directionally consistent results (ESM Tables 10-12).

\section{Discussion}

Previous studies have linked WAT CpG methylation to adiposity and type 2 diabetes. Here, for the first time we report a comprehensive analysis of IR-associated DMS and their correlation with gene expression in SAT and VAT.

VAT mass is more strongly associated with IR than SAT, as reviewed [26]. In our genome-wide transcriptome analysis, however, there were a greater number of genes that were differentially expressed in SAT than in VAT in the insulin-resistant state. Nevertheless, the majority of the IR-associated genes displayed differences in expression that were directionally consistent between SAT and VAT. Together, these data suggest that there is no depot-specific transcriptomic signature that is associated with systemic IR. In agreement with this, Klimcáková et al reported similar alterations in the two adipose depots of obese patients with unfavourable metabolic status [27]. This suggests that other factors, such as the amount of VAT or the metabolite profile, could be more important for determining the effect of VAT on IR or other metabolic disorders. We confirm that IR-associated genes in WAT are over-represented for pathways related to immune response and angiogenesis (VEGFR signalling in the present study), whereas reported overrepresentation of genes important for cell cycle regulation and metabolism was not observed [21, 22]. The reason for the latter discrepancy could be due to selection of study participants.

There were no global differences in DNA methylation between the insulin-resistant and insulin-sensitive women in any of the studied tissues. A number of genes in both SAT and VAT displayed differential methylation accompanied by differential gene expression in insulin-resistant as compared with insulin-sensitive women. We did not observe any significant DMS between the insulin-resistant and insulin-sensitive groups after adjustment for multiple testing in the present dataset. However, considering all nominally significant DMS in the present study (which admittedly include false-positives), the vast majority of DMS that overlap between the present study and previous studies of BMI or type 2 diabetes display directionally consistent methylation differences in the reported cohorts. Furthermore, of the DMS analysed by EpiTYPER, seven had been previously reported and they were all confirmed. This observation suggests that many DMS are real, despite not reaching formal statistical significance in the present study. Traditionally, methylation of $\mathrm{CpG}$ islands in promoters has been associated with repression of gene expression whereas $\mathrm{CpG}$ sites in gene 
Table 4 A subset of differentially expressed genes accompanied by DMS in SAT between insulin-resistant vs insulin-sensitive women ${ }^{\mathrm{a}}$

\begin{tabular}{|c|c|c|c|c|c|c|c|c|c|c|c|}
\hline \multirow[t]{2}{*}{ Probe } & \multirow[t]{2}{*}{ Gene } & \multirow{2}{*}{$\begin{array}{l}\text { Relation to } \\
\text { gene region }\end{array}$} & \multicolumn{6}{|c|}{ DNA methylation } & \multicolumn{3}{|c|}{ Gene expression } \\
\hline & & & IS average & IR - IS & $p$ value & $\mathrm{T} 2 \mathrm{D}^{\mathrm{b}, \mathrm{c}}[10]$ & $\mathrm{BMI}^{\mathrm{b}, \mathrm{d}}[20]$ & $\mathrm{GBP}^{\mathrm{b}, \mathrm{e}}[12]$ & IS average & $\mathrm{IR} / \mathrm{IS}$ & $p$ value \\
\hline $\operatorname{cg} 07251857$ & ALPK3 & 1st exon & 0.546 & 0.026 & 0.022 & & 0.016 & & 76 & 0.89 & $2.56 \times 10^{-3}$ \\
\hline $\operatorname{cg} 06532379$ & $A L P K 3$ & 1st exon & 0.193 & 0.039 & 0.015 & & 0.015 & & 76 & 0.89 & $2.56 \times 10^{-3}$ \\
\hline $\operatorname{cg} 14080050$ & B4GALT1 & Body & 0.447 & -0.037 & 0.015 & & -0.014 & & 228 & 1.10 & $1.48 \times 10^{-3}$ \\
\hline $\operatorname{cg} 13858803$ & B4GALT1 & Body & 0.566 & 0.027 & 0.040 & & 0.027 & & 228 & 1.10 & $1.48 \times 10^{-3}$ \\
\hline $\operatorname{cg} 00300298$ & $B C L 2 L 1$ & Body & 0.251 & -0.037 & 0.038 & & -0.019 & & 151 & 1.07 & $2.01 \times 10^{-3}$ \\
\hline $\operatorname{cg} 12873919$ & $B C L 2 L 1$ & Body & 0.504 & -0.036 & 0.032 & & & & 151 & 1.07 & $2.01 \times 10^{-3}$ \\
\hline $\operatorname{cg} 03290977$ & ClQTNF7 & Body & 0.247 & -0.035 & 0.034 & & -0.024 & & 44 & 0.86 & $3.28 \times 10^{-3}$ \\
\hline $\operatorname{cg} 01939704$ & ClQTNF7 & Body & 0.616 & 0.020 & 0.022 & & & & 44 & 0.86 & $3.28 \times 10^{-3}$ \\
\hline $\operatorname{cg} 07538039$ & CIQTNF7 & Body & 0.610 & 0.025 & 0.021 & & & & 44 & 0.86 & $3.28 \times 10^{-3}$ \\
\hline $\operatorname{cg} 06097727$ & ClQTNF7 & Body & 0.547 & 0.035 & 0.043 & & 0.016 & & 44 & 0.86 & $3.28 \times 10^{-3}$ \\
\hline $\operatorname{cg} 24829483$ & ClQTNF7 & $5^{\prime} \mathrm{UTR}$ & 0.633 & 0.039 & 0.034 & & & & 44 & 0.86 & $3.28 \times 10^{-3}$ \\
\hline $\operatorname{cg} 00545229$ & ClQTNF7 & TSS200 & 0.563 & 0.041 & 0.018 & & & & 44 & 0.86 & $3.28 \times 10^{-3}$ \\
\hline $\operatorname{cg} 15372098$ & C3orf26 & Body & 0.027 & -0.016 & 0.014 & & & & 69 & 0.92 & $3.98 \times 10^{-4}$ \\
\hline cg00991994 & C3orf26 & Body & 0.401 & 0.055 & 0.039 & 0.067 & 0.035 & & 69 & 0.92 & $3.98 \times 10^{-4}$ \\
\hline $\operatorname{cg} 17351376$ & $C D 248$ & 1st exon & 0.504 & 0.019 & 0.032 & & & & 239 & 1.42 & $1.03 \times 10^{-3}$ \\
\hline $\operatorname{cg} 07145284$ & CD248 & TSS200 & 0.085 & 0.029 & 0.038 & & 0.018 & & 239 & 1.42 & $1.03 \times 10^{-3}$ \\
\hline $\operatorname{cg} 00350296$ & $C D 248$ & TSS1500 & 0.158 & 0.041 & 0.018 & & 0.022 & & 239 & 1.42 & $1.03 \times 10^{-3}$ \\
\hline $\operatorname{cg} 13860849$ & $C D 248$ & 1st exon & 0.191 & 0.054 & 0.002 & & 0.015 & & 239 & 1.42 & $1.03 \times 10^{-3}$ \\
\hline $\operatorname{cg} 10772263$ & CHST3 & 5'UTR & 0.322 & 0.020 & 0.028 & & 0.025 & & 113 & 1.17 & $1.31 \times 10^{-3}$ \\
\hline $\operatorname{cg} 04268405$ & CHST3 & TSS1500 & 0.369 & 0.042 & 0.024 & & & 0.219 & 113 & 1.17 & $1.31 \times 10^{-3}$ \\
\hline $\operatorname{cg} 12081643$ & COL4A1 & 3'UTR & 0.670 & -0.042 & 0.008 & & & & 530 & 1.17 & $1.34 \times 10^{-3}$ \\
\hline cg20818806 & COL4A1 & Body & 0.299 & 0.042 & 0.019 & & & & 530 & 1.17 & $1.34 \times 10^{-3}$ \\
\hline $\operatorname{cg} 02658690$ & COL4A1 & Body & 0.207 & 0.042 & 0.014 & & & 0.218 & 530 & 1.17 & $1.34 \times 10^{-3}$ \\
\hline $\operatorname{cg} 10908116$ & COL4A1 & Body & 0.247 & 0.043 & 0.017 & 0.053 & 0.026 & & 530 & 1.17 & $1.34 \times 10^{-3}$ \\
\hline $\operatorname{cg} 02099572$ & COLAAI & Body & 0.140 & 0.047 & 0.005 & 0.056 & & & 530 & 1.17 & $1.34 \times 10^{-3}$ \\
\hline $\operatorname{cg} 03430597$ & COL5A1 & Body & 0.751 & 0.018 & 0.004 & & 0.018 & & 162 & 1.10 & $5.97 \times 10^{-4}$ \\
\hline cg24354213 & COL5A1 & Body & 0.601 & 0.027 & 0.023 & & 0.014 & & 162 & 1.10 & $5.97 \times 10^{-4}$ \\
\hline $\operatorname{cg} 14274542$ & COL5AI & Body & 0.596 & 0.037 & 0.019 & & 0.012 & & 162 & 1.10 & $5.97 \times 10^{-4}$ \\
\hline $\operatorname{cg} 10765212$ & COL5A2 & TSS200 & 0.129 & 0.021 & 0.047 & & & & 246 & 1.20 & $3.25 \times 10^{-4}$ \\
\hline $\operatorname{cg} 15194531$ & $F M N L 1$ & Body & 0.466 & 0.041 & 0.005 & & 0.018 & & 165 & 1.09 & $5.32 \times 10^{-4}$ \\
\hline $\operatorname{cg} 08145262$ & $F R S 2$ & $5^{\prime} \mathrm{UTR}$ & 0.658 & 0.031 & 0.020 & & 0.020 & & 155 & 0.93 & $1.64 \times 10^{-3}$ \\
\hline $\operatorname{cg} 19563525$ & $F R S 2$ & $5^{\prime} \mathrm{UTR}$ & 0.382 & 0.035 & 0.006 & & 0.017 & & 155 & 0.93 & $1.64 \times 10^{-3}$ \\
\hline $\operatorname{cg} 10227830$ & $G A B 1$ & Body & 0.272 & 0.039 & 0.016 & & & & 141 & 0.89 & $1.53 \times 10^{-4}$ \\
\hline $\operatorname{cg} 25911551$ & $G A B 1$ & Body & 0.494 & 0.046 & 0.049 & & 0.019 & & 141 & 0.89 & $1.53 \times 10^{-4}$ \\
\hline $\operatorname{cg} 08202226$ & GATAD2B & TSS1500 & 0.793 & -0.057 & 0.018 & & -0.029 & & 282 & 0.94 & $3.97 \times 10^{-3}$ \\
\hline $\operatorname{cg} 05514401$ & IRS2 & 1st exon & 0.792 & 0.031 & 0.002 & & 0.028 & & 242 & 0.85 & $1.24 \times 10^{-3}$ \\
\hline $\operatorname{cg} 11624345$ & KCNN4 & Body & 0.391 & 0.025 & 0.025 & & 0.014 & & 87 & 1.06 & $4.11 \times 10^{-3}$ \\
\hline $\operatorname{cg} 03731131$ & KCNN4 & Body & 0.378 & 0.032 & 0.039 & & & & 87 & 1.06 & $4.11 \times 10^{-3}$ \\
\hline cg22904711 & KCNN4 & Body & 0.313 & 0.060 & 0.002 & 0.047 & 0.015 & & 87 & 1.06 & $4.11 \times 10^{-3}$ \\
\hline $\operatorname{cg} 14616541$ & МYH10 & Body & 0.834 & 0.024 & 0.010 & & & & 292 & 0.87 & $1.64 \times 10^{-3}$ \\
\hline $\operatorname{cg} 22588546$ & МYH10 & Body & 0.496 & 0.047 & 0.008 & 0.039 & & & 292 & 0.87 & $1.64 \times 10^{-3}$ \\
\hline cg21542094 & PFKFB3 & TSS1500 & 0.081 & -0.001 & 0.025 & & -0.013 & & 542 & 0.80 & $5.53 \times 10^{-5}$ \\
\hline $\operatorname{cg} 00902516$ & PFKFB3 & Body & 0.739 & 0.020 & 0.019 & & 0.016 & & 542 & 0.80 & $5.53 \times 10^{-5}$ \\
\hline $\operatorname{cg} 03261682$ & PFKFB3 & Body & 0.780 & 0.028 & 0.006 & & 0.026 & & 542 & 0.80 & $5.53 \times 10^{-5}$ \\
\hline $\operatorname{cg} 05686026$ & PFKFB 3 & Body & 0.683 & 0.045 & 0.001 & & 0.033 & & 542 & 0.80 & $5.53 \times 10^{-5}$ \\
\hline $\operatorname{cg} 03478610$ & $P P P 2 R 3 A$ & 5'UTR & 0.871 & -0.031 & 0.034 & & -0.014 & & 91 & 0.93 & $1.49 \times 10^{-3}$ \\
\hline $\operatorname{cg} 00369142$ & $P P P 2 R 3 A$ & 3'UTR & 0.378 & 0.044 & 0.013 & 0.060 & 0.025 & & 91 & 0.93 & $1.49 \times 10^{-3}$ \\
\hline
\end{tabular}


Table 4 (continued)

\begin{tabular}{|c|c|c|c|c|c|c|c|c|c|c|c|}
\hline \multirow[t]{2}{*}{ Probe } & \multirow[t]{2}{*}{ Gene } & \multirow{2}{*}{$\begin{array}{l}\text { Relation to } \\
\text { gene region }\end{array}$} & \multicolumn{6}{|c|}{ DNA methylation } & \multicolumn{3}{|c|}{ Gene expression } \\
\hline & & & IS average & $\mathrm{IR}-\mathrm{IS}$ & $p$ value & $\mathrm{T} 2 \mathrm{D}^{\mathrm{b}, \mathrm{c}}[10]$ & $\mathrm{BMI}^{\mathrm{b}, \mathrm{d}}[20]$ & $\mathrm{GBP}^{\mathrm{b}, \mathrm{e}}[12]$ & IS average & IR/IS & $p$ value \\
\hline $\operatorname{cg} 11468953$ & PTPRJ & Body & 0.519 & -0.039 & 0.027 & & -0.020 & & 139 & 1.18 & $3.07 \times 10^{-3}$ \\
\hline $\operatorname{cg} 12124589$ & $Q S O X 1$ & Body & 0.775 & -0.032 & 0.027 & & -0.020 & & 175 & 1.08 & $1.70 \times 10^{-3}$ \\
\hline $\operatorname{cg} 09505809$ & $Q S O X 1$ & TSS1500 & 0.179 & 0.039 & 0.031 & & & & 175 & 1.08 & $1.70 \times 10^{-3}$ \\
\hline $\operatorname{cg} 00971364$ & $R B M S 3$ & TSS200 & 0.043 & -0.018 & 0.034 & & & & 381 & 0.90 & $5.14 \times 10^{-4}$ \\
\hline $\operatorname{cg} 23537305$ & $R B M S 3$ & Body & 0.819 & 0.016 & 0.045 & & 0.017 & & 381 & 0.90 & $5.14 \times 10^{-4}$ \\
\hline cg20299414 & RBMS3 & Body & 0.729 & 0.035 & 0.018 & & 0.013 & & 381 & 0.90 & $5.14 \times 10^{-4}$ \\
\hline $\operatorname{cg} 27569887$ & $R B M S 3$ & 3'UTR & 0.698 & 0.043 & 0.026 & & & & 381 & 0.90 & $5.14 \times 10^{-4}$ \\
\hline $\operatorname{cg} 16572224$ & $S H 3 P X D 2 B$ & Body & 0.816 & -0.049 & 0.002 & -0.039 & -0.019 & & 145 & 1.13 & $4.76 \times 10^{-3}$ \\
\hline $\operatorname{cg} 05223396$ & $S H 3 P X D 2 B$ & Body & 0.404 & 0.025 & 0.049 & & & & 145 & 1.13 & $4.76 \times 10^{-3}$ \\
\hline $\operatorname{cg} 09744420$ & $S T X 11$ & Body & 0.654 & 0.041 & 0.002 & & 0.020 & & 356 & 0.89 & $2.98 \times 10^{-3}$ \\
\hline $\operatorname{cg} 19841369$ & SYNE2 & Body & 0.159 & 0.028 & 0.044 & & 0.016 & & 236 & 0.89 & $2.18 \times 10^{-3}$ \\
\hline $\operatorname{cg} 16725974$ & SYNE2 & 5'UTR & 0.532 & 0.046 & 0.027 & 0.057 & 0.022 & & 236 & 0.89 & $2.18 \times 10^{-3}$ \\
\hline $\operatorname{cg} 23250157$ & $S Y N E 2$ & Body & 0.756 & 0.061 & 0.018 & & & & 236 & 0.89 & $2.18 \times 10^{-3}$ \\
\hline $\operatorname{cg} 18837713$ & ZDHHC17 & Body & 0.616 & 0.045 & 0.010 & & 0.027 & & 161 & 0.94 & $5.15 \times 10^{-3}$ \\
\hline
\end{tabular}

${ }^{a}$ Differentially expressed genes $(10 \%$ FDR) accompanied by DMS $(p<0.05)$ in SAT between insulin-resistant and insulin-sensitive women. Groups were compared using Limma and adjusting for BMI (gene expression, DMS) and age (DMS). This table contains a subset of the ESM Table 4 and focuses on DMS confirmed from the literature and mentioned in the discussion

${ }^{\mathrm{b}}$ Comparison with published transcriptome profiles on SAT from insulin-resistant vs insulin-sensitive individuals

${ }^{\mathrm{c}} \mathrm{T} 2 \mathrm{D}$ vs control

${ }^{\mathrm{d}}$ Regression coefficient

${ }^{\mathrm{e}}$ After vs before bariatric surgery and weight loss

IR, insulin-resistant; IS, insulin-sensitive; T2D, type 2 diabetes

bodies often display a positive association between methylation and expression [23]. In the present study there was no evidence that DNA methylation in the $5^{\prime}$ regions of genes preferentially repressed gene expression, nor the opposite in gene bodies. Interestingly, the link between transcriptional repression and DNA methylation is less clear for non-CpG island promoters (CpG-poor promoters); many active genes have methylated CpG-poor promoters [28]. Together, the

Table 5 Differentially expressed insulin signalling pathway genes accompanied by DMS in SAT between insulin-resistant and insulin-sensitive women $^{\text {a }}$

\begin{tabular}{|c|c|c|c|c|c|c|c|c|c|}
\hline \multirow[t]{2}{*}{ Probe } & \multirow[t]{2}{*}{ Gene } & \multirow{2}{*}{$\begin{array}{l}\text { Relation to } \\
\text { gene region }\end{array}$} & \multicolumn{4}{|c|}{ DNA methylation } & \multicolumn{3}{|c|}{ Gene expression } \\
\hline & & & IR & IS & IR - IS & $p$ value & IS & IR/IS & $p$ value \\
\hline $\operatorname{cg} 17133045$ & AKT3 & Body & $0.761(0.047)$ & $0.735(0.051)$ & 0.026 & 0.007 & 144 & 0.92 & $4.38 \times 10^{-3}$ \\
\hline $\operatorname{cg} 04221461$ & AKT3 & Body & $0.524(0.070)$ & $0.490(0.043)$ & 0.034 & 0.002 & 144 & 0.92 & $4.38 \times 10^{-3}$ \\
\hline $\operatorname{cg} 08428486$ & $B R A F$ & Body & $0.807(0.122)$ & $0.833(0.035)$ & -0.026 & 0.048 & 235 & 0.92 & $3.96 \times 10^{-4}$ \\
\hline $\operatorname{cg} 25204078$ & $B R A F$ & TSS1500 & $0.771(0.040)$ & $0.757(0.042)$ & 0.014 & 0.034 & 235 & 0.92 & $3.96 \times 10^{-4}$ \\
\hline $\operatorname{cg} 06748146$ & $H K 1$ & Body & $0.734(0.047)$ & $0.709(0.044)$ & 0.026 & 0.007 & 170 & 1.09 & $3.07 \times 10^{-3}$ \\
\hline $\operatorname{cg} 05514401$ & $I R S 2$ & 1st exon & $0.823(0.065)$ & $0.792(0.048)$ & 0.031 & 0.002 & 242 & 0.85 & $1.24 \times 10^{-3}$ \\
\hline $\operatorname{cg} 18932526$ & MAPK 8 & TSS1500 & $0.907(0.099)$ & $0.929(0.020)$ & -0.022 & 0.020 & 73 & 0.94 & $3.47 \times 10^{-3}$ \\
\hline $\operatorname{cg} 19612574$ & MAPK 8 & TSS1500 & $0.935(0.074)$ & $0.950(0.019)$ & -0.015 & 0.022 & 73 & 0.94 & $3.47 \times 10^{-3}$ \\
\hline cg20994699 & $P D X 103 A$ & Body & $0.572(0.092)$ & $0.544(0.086)$ & 0.028 & 0.048 & 100 & 0.82 & $4.48 \times 10^{-4}$ \\
\hline $\operatorname{cg} 03465562$ & PHKA2 & Body & $0.929(0.092)$ & $0.953(0.019)$ & -0.024 & 0.021 & 167 & 0.91 & $9.80 \times 10^{-4}$ \\
\hline
\end{tabular}

DNA methylation data are expressed as average (SD); gene expression data are expressed as average

IR, insulin-resistant; IS, insulin-sensitive; TSS1500, within 1500 bp of transcriptional start site 
Table 6 Differentially expressed genes accompanied by DMS in VAT between insulin-resistant and insulin-sensitive women ${ }^{\mathrm{a}}$

\begin{tabular}{|c|c|c|c|c|c|c|c|c|c|c|c|}
\hline \multirow[t]{2}{*}{ Probe } & \multirow[t]{2}{*}{ Gene } & \multirow{2}{*}{$\begin{array}{l}\text { Relation to } \\
\text { gene region }\end{array}$} & \multicolumn{6}{|c|}{ DNA methylation } & \multicolumn{3}{|c|}{ Gene expression } \\
\hline & & & IR & & IS & & IR - IS & $p$ value & IS & $\mathrm{IR} / \mathrm{IS}$ & $p$ value \\
\hline $\operatorname{cg} 17174775$ & $A A S S$ & TSS1500 & 0.016 & 0.039 & 0.027 & 0.033 & -0.011 & 0.0022 & 118 & 0.88 & 0.000121 \\
\hline $\operatorname{cg} 09711028$ & $A B C C 9$ & Body & 0.913 & 0.041 & 0.897 & 0.046 & 0.016 & 0.033 & 391 & 0.86 & 0.000303 \\
\hline $\operatorname{cg} 16236108$ & AGPAT9 & TSS200 & 0.062 & 0.042 & 0.076 & 0.04 & -0.014 & 0.027 & 89 & 0.78 & $7.62 \times 10^{-6}$ \\
\hline $\operatorname{cg} 14229247^{\mathrm{b}}$ & $A N P 32 B$ & TSS1500 & 0.04 & 0.048 & 0.048 & 0.046 & -0.009 & 0.038 & 237 & 0.91 & $3.61 \times 10^{-5}$ \\
\hline $\operatorname{cg} 08400424^{\mathrm{b}}$ & ARHGAP26 & Body & 0.55 & 0.1 & 0.597 & 0.103 & -0.047 & 0.028 & 109 & 1.16 & $2.33 \times 10^{-5}$ \\
\hline $\operatorname{cg} 05185926$ & ARHGAP26 & $3^{\prime} \mathrm{UTR}$ & 0.712 & 0.101 & 0.75 & 0.121 & -0.038 & 0.025 & 109 & 1.16 & $2.33 \times 10^{-5}$ \\
\hline $\operatorname{cg} 11796181^{\mathrm{b}}$ & ARHGAP26 & Body & 0.754 & 0.043 & 0.708 & 0.047 & 0.046 & 0.00017 & 109 & 1.16 & $2.33 \times 10^{-5}$ \\
\hline $\operatorname{cg} 12264626$ & $C A 3$ & TSS1500 & 0.183 & 0.054 & 0.162 & 0.095 & 0.021 & 0.036 & 242 & 0.45 & 0.000136 \\
\hline cg00908631 & $C D K N 2 C$ & TSS1500 & 0.668 & 0.052 & 0.632 & 0.06 & 0.036 & 0.0011 & 134 & 0.82 & 0.000184 \\
\hline $\operatorname{cg} 10156302$ & $D A P K 2$ & Body & 0.605 & 0.091 & 0.552 & 0.111 & 0.053 & 0.01 & 171 & 0.86 & 0.000235 \\
\hline $\operatorname{cg} 23165541$ & $D A P K 2$ & $5^{\prime}$ UTR & 0.403 & 0.094 & 0.363 & 0.09 & 0.039 & 0.014 & 171 & 0.86 & 0.000235 \\
\hline cg06904649 & $D A P K 2$ & Body & 0.767 & 0.037 & 0.744 & 0.043 & 0.022 & 0.043 & 171 & 0.86 & 0.000235 \\
\hline $\operatorname{cg} 16151151$ & ISL1 & Body & 0.196 & 0.069 & 0.172 & 0.095 & 0.024 & 0.016 & 99 & 0.8 & 0.000045 \\
\hline $\operatorname{cg} 17686487$ & ISLI & Body & 0.434 & 0.082 & 0.395 & 0.089 & 0.039 & 0.012 & 99 & 0.8 & 0.000045 \\
\hline $\operatorname{cg} 16270526$ & ISLI & Body & 0.225 & 0.069 & 0.185 & 0.077 & 0.04 & 0.023 & 99 & 0.8 & 0.000045 \\
\hline cg26422022 & $L O X$ & TSS200 & 0.032 & 0.039 & 0.039 & 0.036 & -0.007 & 0.040419 & 169 & 1.22 & $9.74 \times 10^{-5}$ \\
\hline $\operatorname{cg} 22836153$ & $L O X$ & Body & 0.057 & 0.038 & 0.065 & 0.033 & -0.008 & 0.042 & 169 & 1.22 & $9.74 \times 10^{-5}$ \\
\hline $\operatorname{cg} 03422350$ & MOCS1 & Body & 0.722 & 0.068 & 0.68 & 0.071 & 0.042 & 0.031 & 205 & 0.79 & $9.42 \times 10^{-5}$ \\
\hline $\operatorname{cg} 10791278$ & MOCS1 & Body & 0.782 & 0.056 & 0.737 & 0.061 & 0.045 & 0.0016 & 205 & 0.79 & $9.42 \times 10^{-5}$ \\
\hline $\operatorname{cg} 06023702$ & $P A I P 2 B$ & TSS200 & 0.029 & 0.043 & 0.04 & 0.041 & -0.011 & 0.018 & 114 & 0.85 & $5.02 \times 10^{-5}$ \\
\hline $\operatorname{cg} 06241044$ & $P A I P 2 B$ & 5'UTR & 0.265 & 0.052 & 0.242 & 0.066 & 0.023 & 0.038 & 114 & 0.85 & $5.02 \times 10^{-5}$ \\
\hline cg22999327 & $P D E 3 A$ & Body & 0.53 & 0.105 & 0.485 & 0.124 & 0.045 & 0.028 & 133 & 0.82 & $1.19 \times 10^{-5}$ \\
\hline $\operatorname{cg} 02631767$ & PDE3A & Body & 0.875 & 0.056 & 0.857 & 0.058 & 0.018 & 0.048 & 133 & 0.82 & $1.19 \times 10^{-5}$ \\
\hline $\operatorname{cg} 04857033$ & $P H G D H$ & Body & 0.376 & 0.078 & 0.336 & 0.089 & 0.04 & 0.049 & 135 & 0.88 & 0.00039 \\
\hline $\operatorname{cg} 26166935$ & PHLPPI & Body & 0.857 & 0.039 & 0.837 & 0.037 & 0.02 & 0.03 & 101 & 0.91 & 0.000203 \\
\hline cg03299121 & PNOI & TSS200 & 0.055 & 0.044 & 0.064 & 0.041 & -0.01 & 0.0003 & 53 & 1.08 & 0.000385 \\
\hline $\operatorname{cg} 06123940$ & $R N F 125$ & TSS 1500 & 0.798 & 0.044 & 0.785 & 0.043 & 0.012 & 0.029 & 109 & 0.88 & 0.0004 \\
\hline $\operatorname{cg} 18101249$ & RNF125 & Body & 0.082 & 0.049 & 0.089 & 0.037 & -0.006 & 0.046 & 109 & 0.88 & 0.0004 \\
\hline $\operatorname{cg} 13849419$ & $T J P 2$ & Body & 0.509 & 0.095 & 0.468 & 0.106 & 0.041 & 0.043 & 179 & 0.93 & 0.000239 \\
\hline
\end{tabular}

DNA methylation data are expressed as average (SD); gene expression data are expressed as average

${ }^{a}$ Differentially expressed genes $(10 \%$ FDR) accompanied by DMS $(p<0.05)$ in VAT between insulin-resistant and insulin-sensitive women. Groups were compared using Limma and adjusting for BMI (gene expression, DMS) and age (DMS)

${ }^{\mathrm{b}}$ DMS and differentially expressed gene common to SAT and VAT

above findings suggest that the relationship between $\mathrm{CpG}$ methylation and IR is complex, comprising many $\mathrm{CpG}$ sites that have a modest association with IR and a variable impact on gene expression.

There were 223 IR-associated genes with DMS in SAT that were over-represented for pathways related to integrin cell surface interactions, focal adhesion and insulin signalling. Integrins constitute a component of the extracellular matrix and previously have been implicated in adipose remodelling in conjunction with obesity and IR [29, 30]. Specific IRassociated genes with DMS are listed in Table 7, together with potential mechanisms that could explain their association with insulin sensitivity (details on $\mathrm{CpG}$ methylation are given in
Table 4). These specific genes all have DMS that confirm previous findings, and are associated with adipose tissue and insulin signalling in the literature according to PubMatrix (http://pubmatrix.grc.nia.nih.gov/, accessed 31 August 2015).

Although, overall, the CpG methylation in PBMCs did not mirror DMS in SAT associated with IR, a few DMS accompanied by differential gene expression in SAT displayed significant differential methylation in a direction consistent with that in PBMCs. CpG methylation results for FIP1L1 and ADAMTS2 remained directionally consistent in validation experiments. FIPIL1 which encodes FIP 1-like, primarily characterised as a fusion protein (FIP1L1-PDGFRA) in hypereosinophilic disorders [34]. ADAMTS2 encodes 
Table 7 Selected IR-associated genes with DMS

\begin{tabular}{|c|c|c|}
\hline Gene & $\begin{array}{l}\text { Expression and CpG-methylation in SAT: } \\
\text { observations from the current study }\end{array}$ & $\begin{array}{l}\text { Previously reported findings of gene/protein } \\
\text { function }\end{array}$ \\
\hline$G A B 1$ & $\begin{array}{l}\text { SAT CpG methylation in the gene body was } \\
\text { inversely associated with gene expression } \\
\text { and IR was associated with lower } G A B 1 \\
\text { expression (fold change IR vs IS: } 0.89 \text { ) }\end{array}$ & $\begin{array}{l}\text { GAB1 is an adaptor molecule that can stimulate } \\
\text { adipocyte glucose uptake through a GAB1/PI } \\
\text { 3-kinase/PKB/AS160 pathway [31] }\end{array}$ \\
\hline PFKFB3 & $\begin{array}{l}\text { SAT CpG methylation in the promoter was } \\
\text { directly associated with gene expression, } \\
\text { whilst CpG methylation in the gene body } \\
\text { was inversely associated. IR was associated } \\
\text { with lower } P F K F B 3 \text { expression (fold change } \\
\text { IR vs IS: } 0.80 \text { ) }\end{array}$ & $\begin{array}{l}\text { PFKFB3 regulates the steady-state } \\
\text { concentration of fructose-2,6-bisphosphate, } \\
\text { a potent activator of a key regulatory enzyme } \\
\text { of glycolysis. Fat cell overexpression of } \\
\text { PFKFB3 enhances insulin sensitivity [32] }\end{array}$ \\
\hline IRS2 & $\begin{array}{l}\text { SAT CpG methylation in the } 5^{\prime} \text { region was } \\
\text { inversely associated with gene expression } \\
\text { and IR was associated with lower IRS2 } \\
\text { expression (fold change IR vs IS: } 0.85 \text { ) }\end{array}$ & $\begin{array}{l}\text { IRS2 mediates the effects of insulin on glucose } \\
\text { homeostasis and cell growth }\end{array}$ \\
\hline PTPRJ & $\begin{array}{l}\text { SAT CpG methylation in the gene body was } \\
\text { inversely associated with gene expression } \\
\text { and IR was associated with higher PTPRJ } \\
\text { expression (fold change IR vs IS: } 1.18 \text { ) }\end{array}$ & $\begin{array}{l}\text { Recently it was shown that high-fat diet fed } \\
\text { Ptprj-- mice displayed enhanced insulin } \\
\text { sensitivity and improved glucose tolerance, } \\
\text { thus establishing PTPRJ as a negative } \\
\text { regulator of insulin signalling [33] }\end{array}$ \\
\hline
\end{tabular}

AS160, Akt substrate 160-KD; GAB1, growth factor receptor bound protein 2-associated binding protein 1; PFKFB3, 6-phosphofructo-2-kinase/fructose-2,6-biphosphatase 3; PI 3-kinase, phosphatidylinositol 3-kinase; PKB, protein kinase B; PTPRJ, protein-tyrosine phosphatases, receptor-type, J procollagen I N-proteinase that excises the N-propeptide of type I and type II procollagens. Mutation in ADAMTS2 causes the connective tissue disease Ehlers-Danlos syndrome. None of these genes have been characterised in relation to insulin sensitivity. Neither PBMC, SAT nor VAT DNA methylation signatures could confirm the previously reported association of global leucocyte DNA methylation with IR [35]. Furthermore, a DMS in the $A B C G 1$ gene in T cells that previously has been associated with HOMA-IR was not detected in the present study [13]. In most cases differences in both gene expression and DNA methylation between groups in the present study were small. One reason for the small differences in DNA methylation could be that DNA from adipose tissue, which contains different cell types having potentially different DNA methylation signatures, were studied. Similarly we investigated unfractionated PBMCs, and the DNA methylation pattern in subpopulations of these cells may differ [9].

There are sex differences in insulin sensitivity [36] and since we only investigated women it is unknown at present whether DNA methylation may have a different role for IR in obese men.

\section{Conclusion}

Whereas global DNA CpG methylation in adipose tissue is not associated with systemic IR, specific genes display differential expression in SAT accompanied by DMS. Such genes include GAB1, IRS2, PFKFB3, and PTPRJ. Further analysis of the function and epigenetic regulation of these genes in fat cells will help determine their potential causal role in systemic IR. CpG methylation in PBMCs does not reflect DMS in WAT, suggesting that epigenetic analyses in circulating leucocytes are not suitable for metabolic phenotyping of obese individuals.

Acknowledgements The microarray hybridisations were done at BEA (www.bea.ki.se). We wish to thank M. Rönnholm and P. Muller for excellent technical assistance with the array assays (Karolinska Institutet, Stockholm, Sweden). We thank the Mutation Analysis Core Facility (MAF) at the Karolinska University Hospital (Stockholm, Sweden) for their support with the EpiTYPER assay, especially A.-C. Rönn. This study was supported by the SRP Diabetes program at Karolinska Institutet, CIMED, the Swedish Research Council, the Erling-Persson Family Foundation, Novo Nordisk Foundation, EASD/Eli-Lilly Foundation, the Swedish Diabetes Foundation and the EU/EFPIA Innovative Medicines Initiative Joint Undertaking (EMIF grant no. 115372).

Duality of interest ASS, HX, DW, DKR and TJ are employed by GlaxoSmithKline. XY is employed by Janssen. AKL is employed by Pfizer. All other authors declare that there is no duality of interest associated with their contribution to this manuscript.

Contribution statement PA and MR planned the project. ID, AT, MR, $\mathrm{EN}$ and PA were responsible for acquisition of data. ID, IS, ASS, HX, JMF, DW, DR, AKL, TJ and XY analysed data. ID wrote the draft manuscript. All authors contributed to the interpretation of data and revision of the manuscript draft, and approved the final version. PA is the guarantor of this work. 
Open Access This article is distributed under the terms of the Creative Commons Attribution 4.0 International License (http:// creativecommons.org/licenses/by/4.0/), which permits unrestricted use, distribution, and reproduction in any medium, provided you give appropriate credit to the original author(s) and the source, provide a link to the Creative Commons license, and indicate if changes were made.

\section{References}

1. Langenberg C, Sharp SJ, Schulze MB et al (2012) Long-term risk of incident type 2 diabetes and measures of overall and regional obesity: the EPIC-InterAct case-cohort study. PLoS Med 9:e1001230

2. Vaag A, Lehtovirta M, Thye-Ronn P, Groop L (2001) Metabolic impact of a family history of Type 2 diabetes. Results from a European multicentre study (EGIR). Diabet Med 18:533-540

3. Landin K, Lonnroth P, Krotkiewski M, Holm G, Smith U (1990) Increased insulin resistance and fat cell lipolysis in obese but not lean women with a high waist/hip ratio. Eur J Clin Investig 20:530-535

4. Lam TK, Yoshii H, Haber CA et al (2002) Free fatty acid-induced hepatic insulin resistance: a potential role for protein kinase C-delta. Am J Physiol Endocrinol Metab 283:E682-E691

5. Ravussin E, Smith SR (2002) Increased fat intake, impaired fat oxidation, and failure of fat cell proliferation result in ectopic fat storage, insulin resistance, and type 2 diabetes mellitus. Ann N Y Acad Sci 967:363-378

6. Xu H, Barnes GT, Yang Q et al (2003) Chronic inflammation in fat plays a crucial role in the development of obesity-related insulin resistance. J Clin Invest 112:1821-1830

7. Ravelli AC, van der Meulen JH, Michels RP et al (1998) Glucose tolerance in adults after prenatal exposure to famine. Lancet 351:173-177

8. Gluckman PD, Hanson MA, Buklijas T, Low FM, Beedle AS (2009) Epigenetic mechanisms that underpin metabolic and cardiovascular diseases. Nat Rev Endocrinol 5:401-408

9. Reinius LE, Acevedo N, Joerink M et al (2012) Differential DNA methylation in purified human blood cells: implications for cell lineage and studies on disease susceptibility. PLoS One 7:e41361

10. Nilsson E, Jansson PA, Perfilyev A et al (2014) Altered DNA methylation and differential expression of genes influencing metabolism and inflammation in adipose tissue from subjects with type 2 diabetes. Diabetes 63:2962-2976

11. Agha G, Houseman EA, Kelsey KT, Eaton CB, Buka SL, Loucks EB (2014) Adiposity is associated with DNA methylation profile in adipose tissue. Int J Epidemiol 44:1277-1287

12. Benton MC, Johnstone A, Eccles D et al (2015) An analysis of DNA methylation in human adipose tissue reveals differential modification of obesity genes before and after gastric bypass and weight loss. Genome Biol 16:8

13. Hidalgo B, Irvin MR, Sha J et al (2014) Epigenome-wide association study of fasting measures of glucose, insulin, and HOMA-IR in the Genetics of Lipid Lowering Drugs and Diet Network study. Diabetes 63:801-807

14. Bonora E, Targher G, Alberiche M et al (2000) Homeostasis model assessment closely mirrors the glucose clamp technique in the assessment of insulin sensitivity: studies in subjects with various degrees of glucose tolerance and insulin sensitivity. Diabetes Care 23:57-63

15. Lofgren P, Andersson I, Adolfsson B et al (2005) Long-term prospective and controlled studies demonstrate adipose tissue hypercellularity and relative leptin deficiency in the postobese state. J Clin Endocrinol Metab 90:6207-6213

16. Zhang B, Kirov S, Snoddy J (2005) WebGestalt: an integrated system for exploring gene sets in various biological contexts. Nucleic Acids Res 33:W741-W748
17. Dahlman I, Sinha I, Gao H et al (2015) The fat cell epigenetic signature in post-obese women is characterized by global hypomethylation and differential DNA methylation of adipogenesis genes. Int J Obes (Lond) 39:910-919

18. Smyth GK (2005) Limma: linear models for microarray data. In: Gentleman RCV, Dudoit S, Irizarry R, Huber W (eds) Bioinformatics and computational biology solutions using $\mathrm{R}$ and Bioconductor. Springer, New York, pp 397-420

19. Fraga MF, Ballestar E, Paz MF et al (2005) Epigenetic differences arise during the lifetime of monozygotic twins. Proc Natl Acad Sci U S A 102:10604-10609

20. Rönn T, Volkov P, Gillberg L et al (2015) Impact of age, BMI and HbAlc levels on the genome-wide DNA methylation and mRNA expression patterns in human adipose tissue and identification of epigenetic biomarkers in blood. Hum Mol Genet 24:3792-3813

21. Elbein SC, Kern PA, Rasouli N, Yao-Borengasser A, Sharma NK, Das SK (2011) Global gene expression profiles of subcutaneous adipose and muscle from glucose-tolerant, insulin-sensitive, and insulinresistant individuals matched for BMI. Diabetes 60:1019-1029

22. Qatanani M, Tan Y, Dobrin R et al (2013) Inverse regulation of inflammation and mitochondrial function in adipose tissue defines extreme insulin sensitivity in morbidly obese patients. Diabetes 62:855-863

23. Ball MP, Li JB, Gao Y et al (2009) Targeted and genome-scale strategies reveal gene-body methylation signatures in human cells. Nat Biotechnol 27:361-368

24. Guenard F, Tchernof A, Deshaies Y et al (2014) Differential methylation in visceral adipose tissue of obese men discordant for metabolic disturbances. Physiol Genomics 46:216-222

25. Houseman EA, Molitor J, Marsit CJ (2014) Reference-free cell mixture adjustments in analysis of DNA methylation data. Bioinformatics 30:1431-1439

26. Tchernof A, Despres JP (2013) Pathophysiology of human visceral obesity: an update. Physiol Rev 93:359-404

27. Klimcáková E, Roussel B, Marquez-Quinones A et al (2011) Worsening of obesity and metabolic status yields similar molecular adaptations in human subcutaneous and visceral adipose tissue: decreased metabolism and increased immune response. J Clin Endocrinol Metab 96:E73-E82

28. Issa JP, Just W (2011) Epigenetics. FEBS Lett 585:1993

29. Spencer M, Yao-Borengasser A, Unal R et al (2010) Adipose tissue macrophages in insulin-resistant subjects are associated with collagen VI and fibrosis and demonstrate alternative activation. Am J Physiol Endocrinol Metab 299:E1016-E1027

30. Henegar C, Tordjman J, Achard V et al (2008) Adipose tissue transcriptomic signature highlights the pathological relevance of extracellular matrix in human obesity. Genome Biol 9:R14

31. Bertola A, Bonnafous S, Cormont M et al (2007) Hepatocyte growth factor induces glucose uptake in 3T3-L1 adipocytes through A Gab1/phosphatidylinositol 3-kinase/Glut4 pathway. J Biol Chem 282:10325-10332

32. Huo Y, Guo X, Li H et al (2012) Targeted overexpression of inducible 6-phosphofructo-2-kinase in adipose tissue increases fat deposition but protects against diet-induced insulin resistance and inflammatory responses. J Biol Chem 287:21492-21500

33. Kruger J, Brachs S, Trappiel M et al (2015) Enhanced insulin signaling in density-enhanced phosphatase-1 (DEP-1) knockout mice. Mol Metab 4:325-336

34. Cools J, Stover EH, Wlodarska I, Marynen P, Gilliland DG (2004) The FIP1L1-PDGFR $\alpha$ kinase in hypereosinophilic syndrome and chronic eosinophilic leukemia. Curr Opin Hematol 11:51-57

35. Burghardt KJ, Goodrich JM, Dolinoy DC, Ellingrod VL (2015) DNA methylation, insulin resistance and second-generation antipsychotics in bipolar disorder. Epigenomics 7:343-352

36. Geer EB, Shen W (2009) Gender differences in insulin resistance, body composition, and energy balance. Gend Med 6(suppl 1):60-75 